\title{
AVALIAÇÃO PARTICIPATIVA NOS ESPAÇOS PEDAGÓGICOS: ANÁLISE DE UMA INSTITUIÇÃO ESCOLAR DO NORTE DO BRASIL \\ http://dx.doi.org/10.5902/2318133840714
}

\author{
Maria Raimunda Lima Valle ${ }^{1}$ \\ Daniel Nascimento-e-Silva² \\ Ronison Oliveira da Silva ${ }^{3}$
}

\begin{abstract}
Resumo
Este estudo tem por objetivo analisar se a experiência de avaliação praticada em espaço pedagógico de uma instituição do Norte do Brasil é participativa. Buscou-se responder a duas indagações: quais são os tipos de avaliação praticadas naquele espaço pedagógico e quais foram as etapas percorridas para realizar essas avaliações. Trata-se de uma pesquisa bibliográfica seguida da aplicação de questionário contendo perguntas abertas. Os resultados mostram que não há avaliação participativa nos espaços pedagógicos na instituição pesquisada e apontam a avaliação teórica e prática como os dois tipos de avaliações mais praticadas pelos professores da educação profissional básica e superior da região Norte do Brasil.

Palavras-chave: avaliação; participação; espaço pedagógico.
\end{abstract}

\section{PARTICIPATORY ASSESMENT IN PEDAGOGICAL SPACES: AN ANALYSIS OF A NORTH BRAZILIAN SCHOOL INSTITUTION}

\begin{abstract}
The objective of this study is to analyze if the evaluation experience practiced in a pedagogical space of an institution in Northern Brazil is participative. We sought to answers two questions: what are types of assessment practiced in that pedagogical space? What were the steps taken to perform these assessment's? This is a bibliographic search followed by the application of questionnaire containing open questions. The results show that there is not participatory assessment in the pedagogical spaces in the researched institution and point the theoretical and practical evaluation as the two types of evaluations most practiced by teachers of basic and higher professional education in Northern Brazil.

Key-words: evaluation; participation; pedagogical spaces.
\end{abstract}

\footnotetext{
1 Instituto Federal do Amazonas, campus Manaus Centro, Brasil. E-mail: mrlv.bianca@gmail.com.

2 Instituto Federal do Amazonas, campus Manaus Distrito Industrial. E-mail: danielnss@gmail.com.

3 Instituto Federal do Amazonas, campus Manaus Centro. E-mail: ronison.msc@gmail.com.
}

Regae: Rev. Gest. Aval. Educ. 


\section{Introdução}

avaliação é uma das etapas do mecanismo de controle, fundamental para
que o processo gerencial possa ser elaborado e implantado com a maior
probabilidade possível de sucesso (Nascimento-e-Silva et al, 2013). Sem avaliação, portanto, dificilmente os objetivos organizacionais poderão ser alcançados porque é o produto da avaliação que assegura se aquilo que foi efetivamente realizado está ou não em conformidade com 0 que se pretendida realizar. Nos espaços pedagógicos, consequentemente, a avaliação se reveste de caráter de maior essencialidade, porque lida não apenas com o aperfeiçoamento cognitivo das pessoas, mas com o seu comportamento.

São muitos os casos de experiências de processos avaliativos encontrados na literatura, mas poucos se revestem da natureza científica e seu rigor, de maneira que se possa tê-los como referências seguras, tanto para a compreensão do fenômeno, quanto para a sua aplicação prática por modelos empiricamente validados.

Dessa forma, este estudo tem como objetivo fazer um levantamento das modalidades de avaliação praticadas em determinado espaço pedagógico de oferta de curso técnico de nível médio integrado de uma instituição federal de educação profissional e tecnológica com a finalidade de compreender suas etapas operacionais. Em termos específicos pretende-se responder a duas perguntas: Quais são os tipos de avaliação praticadas nesse espaço pedagógico? Quais foram as etapas percorridas para realizar essas avaliações?

\section{Gestão participativa e avaliação}

Gestão é o processo de planejar, organizar, dirigir e controlar recursos para o alcance dos objetivos organizacionais (Nascimento-e-Silva, 2011). Isso significa que os recursos são o centro da atenção do esforço de gestão, de maneira que os objetivos tenham o máximo de probabilidade de serem alcançados. Isto é consequência do uso racional - planejado, organizado, dirigido e controlado - dos recursos e vale para todo e qualquer tipo de organização, o que inclui os espaços pedagógicos.

A avaliação, por sua vez, faz parte da quarta etapa do processo gerencial, isto é, o controle. Controlar é buscar assegurar que o objetivo pretendido seja alcançado, a partir da estratégia elaborada e com o uso dos recursos disponíveis. O processo de controle começa com a definição de padrões, a elaboração de um sistema de mensuração, prossegue com a avaliação e termina com o replanejamento daquilo que não saiu em conformidade com o esperado (Nascimento-e-Silva et. al., 2013). Avaliar significa, então, comparar o que foi feito com aquilo que era esperado. O desafio é fazer isso de forma participativa, ou seja, com a contribuição de todos aqueles que operam no espaço pedagógico.

A gestão participativa nos espaços pedagógicos em educação profissional e tecnológica - EPT - precisa ser estabelecida. No mundo globalizado não é mais admissível que poucos decidam e definam os objetivos e o futuro de uma determinada instituição, seja esta pública ou privada. De acordo com Kudo, Fernandes e Silva (2016), participação é definida como uma forma de governança. A expressão 'uma forma' implica 
deduzir a existência de outras formas de participações. Por sua vez, governança contempla duas etapas básicas: decisão e execução. De igual forma, decisão envolve escolhas, assim como execução envolve ação.

Malta (2015) afirma que a participação pode ser definida como uma ação social que tem como finalidade interferir diretamente nas decisões e nas ações referentes à planificação, atuação e avaliação da atividade que se desenvolve. Nesse sentido, pode-se inferir que os processos das escolhas - decisões - devem levar em consideração a organização, atuação e o desempenho das atividades deliberadas com vista no cumprimento ou não de sua intencionalidade.

A participação pode ser definida como a ação ou o resultado de compartilhar ou ter parte em algo (Fernandes, 2015). Nessa perspectiva observa-se que o fazer e o ter parte em algo, decidido e executado conjuntamente com outros sujeitos, é possível de ser compartilhado, uma vez que compartilhar indica, pelo menos, uma ação realizada por duas pessoas. O sentimento de pertencimento e de integração poderá ter consequências favoráveis nos processos decisórios e contribuir com resultados satisfatórios.

Goulart, Terci e Otero (2015) definem participação como formas diferenciadas de incorporação de cidadãos e associações da sociedade civil na deliberação sobre políticas, permeada por interesses corporativos e particulares que refletem a multiplicidade das sociedades contemporâneas. A participação seria categoria nativa da prática política de atores sociais, categoria teórica da teoria democrática e procedimento institucionalizado com funções delimitadas por leis e disposições regimentais. Deduz-se que a participação de cidadãos e de associações da sociedade civil ocorre de diferentes formas que visam à integração.

Nichols (2014), ao analisar a participação política, apresenta dois tipos de participação: participação convencional e não convencional. Explica, ainda, que a principal diferença entre estas está na arena em que são aplicadas. Assim, as formas convencionais de participação englobariam atos relacionados com os processos eleitorais, tais como o voto, as atividades de campanha, contato personalizado, doação de dinheiro para campanhas e discussão sobre política. Diferentemente, a participação não convencional abarca métodos de pressão situados fora da esfera político-institucional, como manifestações e greves, por exemplo. Em síntese, existem dois tipos de participação: a participação corriqueira e habitual e aquela que foge totalmente aos padrões comuns. A diferença entre a participação convencional e não convencional consiste no contexto em que elas ocorrem.

No contexto da pesquisa-ação participativa em saúde, Carvalho e Rodrigues (2018) e Cornwall (2008) identificaram seis tipos de participação: cooptação, conformidade, consulta, cooperação, co-aprendizagem e ação coletiva. Barki e Hartwick (1989) apresentam três tipos de participação: engajamento, participação e envolvimento. Caixeta e Fabrício (2018) também abordam os três níveis de participação propostos por Damodaran (1996) na área de projetos de tecnologia de informação que podem ser considerados para a área de projeto de Arquitetura: informativo: usuários apenas fornecem ou recebem informações; consultivo: usuários são envolvidos para comentar um serviço ou conjunto de componentes pré-definidos; participativo: usuários influenciam decisões relativas a todo o sistema. 
De maneira análoga Carvalho e Rodrigues (2018) dividem as etapas do processo de participação em três níveis: Poder do Cidadão, com as subcategorias Controle do Cidadão, Poder delegado, Parceria, o Tokenismo, com as subcategorias Colocação, Consulta e informação e a Não Participação, com as subcategorias Terapia e Manipulação. Para os autores é o poder político que está diretamente relacionado com os níveis de participação da comunidade na tomada de decisões. Dito de outra forma, é o poder político que determinará a posição da decisão na escalada do grau inferior ao superior, da manipulação ao controle. O fator determinante aqui é o grau de poder que define a escala de participação para mais para menos ou nula.

Para Ribeiro (2018) o processo de participação deve contemplar as seguintes etapas: identificação dos principais problemas e necessidades; formulação de um projeto preliminar; geração de opções e alternativas de concessão para as medidas e soluções; escolha de uma opção de projeto. Verifica-se que, neste caso, há ausência de hierarquia de poder nas etapas de participação e que em cada etapa leva-se a indução da participação dos sujeitos.

Segundo Sabioni e Ferreira (2018) as etapas do processo de participação são seis: recebimento das denúncias irregulares; apuração da veracidade das informações; busca de orientação jurídica; coleta de provas das fraudes; abertura de uma ação no ministério público; acompanhamento dos processos nas sessões da Câmara Municipal. Nesse contexto específico, embora os procedimentos sejam rigorosamente pré-estabelecidos com finalidades próprias, observava-se o estabelecimento de etapas sequenciais a serem vencidas.

\section{Avaliação nos espaços pedagógicos}

Para compreender o que é avaliação, especificamente avaliação participativa no âmbito dos espaços pedagógicos, se faz necessário entender o que é avaliação e como ela se desenvolve. Segundo Gariboldi e Pugnaghi (2018) a avaliação que ocorre nas instituições escolares se configura como instrumento de uma abordagem orientada e reflexiva para a formação da equipe educacional, pois traz no centro da análise e reflexão a coerência entre o projeto exposto e a ação de ensino, possibilitando o destaque das implicações pedagógicas das práticas cotidianas e, portanto, estimulando a discussão do significado dentro do grupo, a aprendizagem transformadora e a construção de um projeto educacional mais claro e compartilhado.

Para esclarecer o próprio conceito de avaliação, Gariboldi e Pugnaghi (2018) afirmam que se trata de um processo de avaliação formativa fortemente caracterizado em sentido dialógico e translativo que visa à capturar os diferentes aspectos de uma realidade dinâmica na multiplicidade de pontos de vista, destacando as relações de interdependência entre os vários elementos do contexto para poder raciocinar sobre a complexidade de uma situação educacional. Consequentemente é uma forma de investigação autorreflexiva baseada no envolvimento e participação dos professores, 0 que implica procedimentos sistemáticos de autoanálise da realidade educacional e orientada para o compartilhamento de um repertório interpretativo e avaliador.

Com o objetivo de ampliar a compreensão de avaliação Villa, Saramago e Araújo (2018) contribuem com esta pesquisa analisando o conceito de avaliação pós-ocupação no curso de edificações no contexto de avaliação pós-ocupação que esta pode ser 
definida como um conjunto de métodos e técnicas aplicado a edificações em uso, passado algum tempo de sua entrega definitiva, com o objetivo tanto de medir o desempenho físico das mesmas mediante a análise de especialistas quanto de aferir os níveis de satisfação dos usuários.

Para os autores acima a avaliação pós-ocupação se diferencia das usuais visitas técnicas a edifícios e conjuntos edificados ou mesmo das frequentes e tradicionais análises de estudos de caso, geralmente realizadas em algumas disciplinas de projeto, na medida em que possibilita o conhecimento mais aprofundado das soluções adotadas e de suas consequências para os usuários em termos técnico-construtivos, funcionais, comportamentais e ambientais (Villa, Saramago; Araújo, 2018).

A definição de avaliação de Gariboldi e Pugnaghi (2018) e o estudo sobre a avaliação pós-ocupação de Villa, Saramago e Araújo (2018) possuem pontos comuns referentes à avaliação que se podem verificar facilmente. $O$ primeiro deles é que a avaliação precisa valer-se de instrumentos, métodos e técnicas. O segundo ponto é que ambas envolvem a ação de pessoas na aplicação, participação e análise dos instrumentos avaliativos. O terceiro envolve processos, etapas a serem desenvolvidas e esperam resultados. Por último ambas vislumbram melhorias e soluções de problemas.

Outro importante estudo sobre avaliação é o de Cruz e Almeida (2017) que analisam a questão da gestão pública. Eles afirmam que em relação à avaliação Ala-Harja e Helgason (2000) situam-na como uma prática constituída por análises sistemáticas e de aspectos importantes de um programa e de seu valor, de modo a fornecer conclusões confiáveis e utilizáveis. Complementando tal perspectiva Ramos e Schabbach (2012) e Mokate (2002) destacam que a avaliação pode conduzir à melhoria da eficiência do gasto público, da qualidade da gestão e do controle social sobre a efetividade da ação do Estado. Reforçando as perspectivas apresentadas Thoenig (2000) entende a avaliação como um caminho para o aperfeiçoamento da capacidade de aprender como um processo de conduzir mudanças bem-sucedidas e definir resultados alcançáveis nos campos da eficiência e eficácia públicas.

Para Cruz e Almeida (2017), independentemente da tipologia - diagnóstico, monitoramento, resultados ou impacto - ou do desenho de sua aplicação, faz-se mister reforçar que a avaliação no âmbito das políticas públicas deve ocorrer em todo o seu ciclo, servindo para fins analíticos ou decisórios, extrapolando as visões que a restringem às etapas subsequentes à implementação do programa ou de revisão periódica de uma política (Thoening, 2000). Ou seja, sua condução deve ser transversalmente ajustada às necessidades e possíveis usos por parte dos sujeitos implicados.

Both e Haracemiv (2017) trazem à baila o fato que a avaliação sugere observar aquilo que de fato é essencial, importante e significativo. Contudo, esse contemplar os fatos e a ação dos sujeitos não quer dizer que deva ser realizado de qualquer jeito e de forma despretensiosa, mas requer julgamento justo e equitativo, requer uma intencionalidade e por isso deve ser planejado, deve contemplar procedimentos, deve utilizar instrumentos confiáveis, deve garantir confiabilidade, e acima de tudo, deve propor soluções alternativas e redimensionamento dos objetivos.

Ao abordarem sobre planejamento coletivo por temas e avaliação descritiva em escolas do campo, especificamente a experiência da Escola Básica Municipal José Maria, Borowicc e Zotti (2018) dizem que de acordo com o que determina a LDB, na escola, já 
há alguns anos, a avaliação qualitativa, prepondera sobre a quantitativa. Segundo os autores, os professores da Escola José Maria, em participação de formação pedagógica, decidiram pela implantação de uma nova forma de avaliação.

Esta nova forma de avaliação fora definida no projeto político-pedagógico como avaliação descritiva, à qual seria acrescida das avaliações existentes e praticadas pela escola: diagnóstica e processual: explicam que a avaliação diagnóstica visa a determinar a presença ou a ausência de conhecimentos e habilidades, objetivando saber em qual nível encontra-se o aluno para compreender o processo da produção do conhecimento, a fim de planejar as próximas intervenções, os conteúdos e as estratégias de ensino mais adequadas para que a aprendizagem aconteça. Nesta instituição, particularmente, buscava-se uma avaliação processual, que percorresse todos os momentos da aprendizagem. Por fim, o objetivo da avaliação descritiva era favorecer a inclusão e a valorização da diversidade, contrapondo-se ao caráter excludente e classificatório que permeou historicamente a avaliação (Borowicc; Zotti, 2018).

Em estudo feito por Blasis (2013) foram encontradas três dimensões avaliativas presentes no cotidiano escolar: avaliação externa: realizada em larga escala, verificando a aprendizagem dos estudantes das redes de ensino; avaliação institucional: traduz o compromisso coletivo da escola com o progresso de cada turma ou aluno; avaliação da aprendizagem: feita pela escola, com fins de diagnóstico, acompanhamento e intervenção em contextos de aprendizagem de cada estudante.

Quanto a avaliação participativa, Cruz e Almeida (2017) acrescentam que se caracteriza como oportunidade para ativar contextos de aprendizagem coletiva e desenvolver as competências dos sujeitos implicados nas políticas e programas. Nessa direção cabe citar o estudo de Vianna e Amaral (2014, p. 32), que mostra que a avaliação participativa abre a possibilidade de desdobramento de um processo de aprendizagem social, situação que, para Roesch (2002), é definida como processo de emancipação dos sujeitos e comunidades. Por sua vez Mokate (2002) ressalta que as ações de monitoramento e avaliação contribuem com os processos dinâmicos de aprendizagem coletiva sobre a realidade de atuação, sobre a execução das políticas, necessidades de eventuais ajustes (Cruz; Almeida, 2017).

Sobre a análise dos tipos de avaliação Figueiredo, Leite e Fernandes (2018), na busca de uma tipologia para a compreensão da avaliação de escolas, selecionaram 73 artigos sobre $o$ assunto e inferiram que a análise desses artigos permitiu identificar quatro eixos relativos à avaliação das escolas: razões para a avaliação das escolas; funções da avaliação das escolas; modalidades seguidas na avaliação das escolas; efeitos gerados pela avaliação das escolas.

Para os autores, a razão que perpassa a avaliação de escolas é justificada no quadro de uma realidade socioeconómico e político que atribui às instituições de ensino a função de suprir as necessidades sociais e laborais, reconhecendo a avaliação de escolas como um meio de regulação dos modos de gestão escolar, e ainda de dar resposta às exigências de promoção de maior qualidade do serviço educativo prestado. De igual modo, as funções atribuídas à avaliação de escolas vão no sentido de dar respostas às 
situações e condições que conduziram à sua implementação. Isto é, a avaliação de escolas surge na literatura com uma dupla finalidade: entre a ideia de promover a melhoria das escolas e dos processos educativos e a accountability do trabalho desenvolvido, da utilização dos recursos e do funcionamento das escolas.

Figueiredo, Leite e Fernandes (2018) afirmam que a pesquisa sobre avaliação de escolas apresentou a existência de duas modalidades: avaliação externa e avaliação interna. Prosseguem explicando que referente aos efeitos possíveis da avaliação de escolas, a literatura analisada permitiu identificar seus efeitos positivos, que correspondem em parte às suas funções e ao potencial que lhe é reconhecido, e efeitos menos positivos e ou menos desejáveis (Dedering; Muller, 2011).

Para Figueiredo, Leite e Fernandes (2018) a definição de avaliação externa corresponde a uma avaliação desenvolvida por agentes externos à escola, normalmente uma equipe de avaliadores que não pertence ao corpo da escola e que tem como função primordial a coleta de informação, a formulação de um juízo de valor e a devolução de suas conclusões à escola (Janssens; Amelsvoort, 2008). Quanto à avaliação interna eles a denominam de autoavaliação que, por definição, é um procedimento avaliativo da responsabilidade dos agentes pertencentes à instituição e que visa a olhar para dentro e de dentro dela, recolhendo informações diagnósticas que permitam fazer o balanço entre o trabalho realizado e os objetivos traçados, bem como identificar pontos fortes, pontos fracos e áreas de intervenção prioritária.

Entre os vários tipos de avaliações vistos até aqui observa-se que Cruz e Almeida (2017), Figueiredo, Leite e Fernandes (2018) apresentam, em comum, dois tipos de avaliações que são identificadas por: a avaliação externa e avaliação interna ou autoavaliação. Como já foi visto a avaliação externa trata de uma avaliação em grande escala e realizada por agente externo à escola e visa regulação, acompanhamento e análise de resultados com vista em investimento de políticas públicas. A avaliação interna, conhecida também por autoavaliação, refere-se àquela que é realizada e conduzida pelos gestores, professores, alunos e demais membros da comunidade escolar, visando à melhoria dos seus serviços, resultados positivos a curto e longo prazo e a satisfação de todos.

Paula, Costa e Lima (2018), ao verificarem a condicionalidade do estado avaliador e suas implicações na avaliação e a expansão mercantilizada da educação superior brasileira, mostram que o Sistema Nacional de Avaliação da Educação Superior - Sinaes surgiu em 2004, com a aprovação da lei n. 10.861, coordenado pela Comissão de Avaliação da Educação Superior - Conaes. Esse processo integra três modalidades de avaliação, de acordo com Lacerda, Ferri e Duarte (2016): processo de avaliação institucional conduzido pelas comissões próprias de avaliação e comissões externas, a avaliação dos cursos de graduação e o Exame Nacional do Desempenho dos Estudantes.

Além da avaliação externa e por se tratar de dispositivos legais emanados do poder público, ao analisarem os tipos de avaliação, na sua maioria os autores se reportam aos três tipos de avaliações que são submetidas as instituições de ensino e as que ela mesma deve realizar: a avaliação institucional ou autoavaliação, sendo esta realizada por uma comissão própria de avaliação no sentido de garantir sua realização, pois na avaliação externa é um dos critérios de verificação; a avaliação de cursos realizada, também, no interior da instituição por professores, alunos e coordenadores de cursos, de igual forma 
regulada pela avaliação externa na ocasião da validação e oferta dos cursos, e avaliação do desempenho dos alunos, de caráter obrigatório para o discente, realizada em grande escala por agentes externos à instituição que visa verificar os conhecimentos adquiridos pelos alunos no início e no fim do curso.

Quanto a avaliação da aprendizagem Santos e Santos (2018) apresentam a questão de que avaliar nem sempre foi uma tarefa fácil. Existe uma diversidade de métodos e práticas para serem empregadas nas práticas avaliativas. Da mesma forma que o indivíduo possui características próprias de aprender, a avaliação também deve ser diferenciada, pois os procedimentos e as técnicas que se aplicam a todos, nem sempre, alcançam resultados de forma igualitária. Para uma sala de aula há pelo menos que ser aplicados vários métodos ou técnicas de avaliação, para a verificação do que o aluno foi capaz de aprender, considerando a individualidade de cada um e o processo avaliativo de cada criança. De modo que há três tipos de avaliação a diagnóstica, formativa e classificatória.

Segundo Santos e Santos (2018) a avaliação diagnóstica permite ao professor identificar as causas de dificuldades específicas dos estudantes na assimilação do conhecimento, tanto relacionadas ao desenvolvimento pessoal, quanto à identificação de quais conteúdo do currículo apresentam necessidades de aprendizagem. A avaliação formativa visa a informar, tanto o professor, quanto o aluno dos rendimentos nas atividades ou sobre os instrumentos avaliativos que estão sendo utilizado e detectar as possíveis dificuldades a serem superadas dentro da escola no processo de avaliação. Por sua vez a avaliação classificatória tem como objetivo medir a capacidade do estudante usando a nota para verificar se ela obteve o resultado.

No que tange a avaliação da aprendizagem e a semelhança de Borowicc e Zotti (2018), Santos e Santos (2018) abordam a avaliação diagnóstica, formativa e classificatória, sendo que para os primeiros autores elas são denominadas de diagnóstica, processual e descritiva contendo concepções teórico-metodológicas diferenciadas. A avaliação diagnóstica está presente no início de todo o processo ensino e aprendizagem e tem como objetivo principal identificar o nível de conhecimento dos educandos frente uma proposta de conteúdo programático de um determinado componente curricular.

Para Moura (2017), de acordo com Oliveira (2013) a avaliação escolar no Brasil contempla três modalidades: a da aprendizagem; a do sistema, ou seja, as avaliações externas, e a institucional. Para a autora os agentes avaliadores se alternam conforme a categoria da avaliação. Na sua concepção, na avaliação da aprendizagem, o agente avaliador é o professor e o avaliado o aluno; no âmbito do sistema, a avaliação passa a ser responsabilidade do Estado, sendo avaliados os alunos, os professores e a escola; na avaliação institucional é a comunidade escolar quem planeja, executa, avalia e toma decisão, aqui o foco é centrado na melhoria dos processos internos do trabalho escolar.

Moura (2017) afirma que a problematização em torno da avaliação da escola tem evidenciado a necessidade de discutir a importância da avaliação institucional como processo que permeia o trabalho educativo, o aprimoramento do processo de gestão escolar e a possibilidade de institucionalização de práticas avaliativas assentadas numa política de mudança e desenvolvimento da qualidade educativa. Para a autora a avaliação institucional é uma nova exigência com a qual as escolas são confrontadas, e precisam aprender a fazer. É um ato de responsabilidade social. 
Por fim, a avaliação é de suma importância para todo processo de gestão, seja administrativo ou pedagógico, pois permite identificar pontos fortes e fracos a serem redimensionados. Como foi percebido até aqui, pode-se resumir que nos diferentes estudos de pesquisa, o processo de avaliação estava presente de uma forma ou de outra, dita de um jeito ou de outro, porém, todos apresentam os tipos de avaliação. Os principais tipos de avaliação decorrem de duas formas: a avaliação da aprendizagem e a avaliação das instituições, seja de ensino ou não.

A avaliação das instituições pode ser externa e interna. No caso das instituições de ensino, inclui-se a avaliação da aprendizagem. A avaliação externa é realizada por agentes externo. A avaliação interna ou autoavaliação é aquela realizada pela própria instituição. Em todos os tipos de avaliação, a avaliação de efeitos integra a avaliação de resultados.

\section{Metodologia}

Para efetivação desta pesquisa foi traçado um caminho metodológico, divididos em tópicos: definição do tema e do espaço pedagógico, pesquisa bibliográfica, instrumentos e técnicas da pesquisa, tratamento dos dados, análise dos dados e apresentação dos resultados. O estudo sobre avaliação está diretamente ligado à gestão e avaliação nos espaços pedagógicos em educação, especificamente, na educação profissional e tecnológica. O espaço pedagógico definido para a pesquisa foi a sala de aula em uma instituição de ensino na região Norte brasileira. A população da pesquisa foram cinco professores com atuação profissional em instituições de ensino básico e superior.

Uma vez definido o tema da avaliação foi realizado o levantamento bibliográfico e busca no Google Acadêmico a partir de artigos científicos, revistas, dissertações de mestrados referentes ao tema avaliação, independentemente da área de estudos, publicados no período de 2017 a 2018. Foram encontrados, entre artigos e dissertações, 21 trabalhos, dos quais 19 foram selecionados por atenderem aos critérios de busca. $A$ elaboração da massa de dados teve como base duas perguntas principais sobre o objeto dessa pesquisa, isto é, qual a definição de avaliação e quais são os tipos, etapas ou processos de avaliações existentes.

Optou-se pela aplicação de um questionário contendo perguntas abertas a cinco docentes. $O$ instrumento utilizado nesta pesquisa, então, foi o questionário que teve como finalidade coletar dados da prática docente em sala de aula: quais os dois tipos de avaliações mais praticados por eles, o que era feito e em quantas etapas eram realizadas as avaliações. Pretendia-se identificar os tipos de avaliações e de que forma essas avaliações eram realizadas na concepção dos respondentes.

Após aplicação e retorno dos questionários pelos voluntários, iniciou-se o tratamento dos dados obtidos que culminaram na elaboração de dois quadros correspondentes a cada pergunta, os quais foram denominados de quadro 1 e quadro 2. Os sujeitos da pesquisa foram mantidos no anonimato e receberam uma identificação pelas primeiras cinco letras do alfabeto, isto é, respondentes A, B, C, D, E e F. O primeiro quadro apresenta duas colunas, uma à direita que concentra os respondentes e, à esquerda, as respostas emitidas por cada respondente sobre a indagação sugerida, ou seja, tratou dos dois tipos de avaliações mais utilizadas pelos docentes. 
O segundo quadro apresenta duas colunas, uma à direita que concentra os respondentes e, à esquerda, as respostas emitidas por cada respondente sobre a indagação sugerida, isto é, como as avaliações eram feitas, quantas etapas eram percorridas, o que eram feitas em cada etapa. Esses dados foram transcritos tal como foram redigidos de cunho próprio pelos participantes, de acordo com cada quadro, pergunta e resposta correspondente.

Durante a análise dos dados obtidos na pesquisa os critérios, tais como: pontos comuns ou semelhantes, pontos divergentes, aspectos diferencias, aspectos inovadores, outros espaços pedagógicos, relação existente entre o espaço pedagógico e o tipo de avaliação, a participação dos alunos no processo da avaliação da aprendizagem, foram considerados entre as respostas dos voluntários. As etapas aqui apontam que em todas as amostras a avaliação escrita e avaliação prática é preponderante, além de que se utilizam, também, dois espaços pedagógicos com finalidades distintas: a sala de aula, onde ocorrem as avaliações escritas, e o laboratório, onde ocorrem as avaliações práticas. Ademais, como essas avaliações são feitas e quantas etapas são percorridas, são completamente semelhantes nos dois tipos de avaliações, mudando-se apenas os instrumentos ora prova ora relatório ou seminário.

\section{Tipos de avaliação mais praticados}

Ao serem indagados sobre quais os dois tipos de avaliação mais praticados no espaço da sala de aula pelos professores, como mostra o quadro 1, o respondente A afirmou que são a avaliação escrita e prática de laboratório com relatórios; o respondente $B$ respondeu que realiza a avaliação prática em laboratório e prova teórica em sala de aula; o respondente $\mathrm{C}$ disse que utiliza a avaliação escrita individual ou em dupla, mais 0 relatório de aula prática; o respondente $\mathrm{D}$ respondeu que utiliza a avaliação escrita dissertativa e defesa de resolução de exercícios no quadro.

$O$ respondente $\mathrm{E}$ disse que usa prova escrita, na qual costuma trabalhar questões diversificadas: de cálculos, de múltipla escolha, e questões dissertativas mais seminários e apresentações: "no decorrer da disciplina, repasso aos alunos conteúdo específicos referentes ao conteúdo que está sendo observado para que estes possam expor de forma oral tanto em sala de aula ou laboratório" (respondente E). Por fim, o respondente F disse fazer avaliação participativa durante as aulas e correção de exercícios, depois avaliação das aulas práticas por meio de relatórios e avaliação de conteúdos por meio de prova com questões objetivas e avaliativas.

Diante dos relatos, pode-se identificar os dois tipos de avaliações mais praticados pelos docentes: a avaliação escrita, em que eles afirmam verificar o conteúdo de natureza teórico da disciplina, e a avaliação prática mediante elaboração de relatório por parte dos alunos das atividades realizadas em laboratórios. É interessante destacar que o respondente $\mathrm{C}$ disse aplicar avaliação escrita individual ou em dupla, permitindo assim a interação dos alunos mesmo que de forma restrita. 
Quadro 1 -

Tipos de avaliação mais praticados.

\begin{tabular}{|c|c|c|c|c|c|}
\hline \multicolumn{7}{|c|}{ Tipos de avaliação } \\
\hline \multirow{2}{*}{ Respondente } & $\begin{array}{c}\text { Prova } \\
\text { teórica } \\
\text { escrita }\end{array}$ & $\begin{array}{c}\text { Prova } \\
\text { prática } \\
\text { relatório }\end{array}$ & $\begin{array}{c}\text { Defesa de } \\
\text { exercício na } \\
\text { lousa }\end{array}$ & $\begin{array}{c}\text { Seminários e } \\
\text { apresentações }\end{array}$ & $\begin{array}{c}\text { Avaliação participativa } \\
\text { correção de exercícios }\end{array}$ \\
\hline A & X & X & & & \\
\hline B & X & X & & & \\
\hline C & X & X & & & \\
\hline D & X & X & X & & \\
\hline E & X & X & & X & \\
\hline F & X & X & & & X \\
\hline
\end{tabular}

Fonte: autores (2018).

Por outro lado, o respondente $\mathrm{D}$ disse abordar a avaliação escrita dissertativa mais o diferencial da defesa de resolução de exercícios no quadro, que, de certa forma, possibilita a interação da turma. $O$ respondente $E$ disse utilizar o seminário e apresentações como avaliação. Os seminários, também, favorecem a participação e a interação dos alunos. De uma forma ou de outra, as duas avaliações da aprendizagem mais utilizadas pelos professores em sala de aula, são as provas escritas e os relatórios das práticas.

As provas escritas, de um modo geral, têm como objetivo mensurar a capacidade de domínio teórico por parte dos alunos; as avaliações práticas são mensuradas por meio da elaboração de relatórios, apresentações, defesas de exercícios e seminários. Esse tipo de avaliação representa a segunda alternativa mais utilizada entre os docentes pesquisados. O respondente $F$, além da avaliação escrita por meio de prova e a avaliação prática através de relatório, citou a avaliação participativa quando desenvolve correção de exercícios durante as aulas.

\section{Etapas do processo de avaliação}

Com base na segunda pergunta de como as duas avaliações mais praticadas pelos professores são feitas e quantas etapas são percorridas e o que é feito em cada etapa, pode-se relatar que 0 respondente $A$ disse que avaliação escrita compreende teoria mais exercícios mais avaliação e que a avaliação de laboratórios, compreende teoria mais prática mais relatório. $O$ respondente $B$ afirmou que

"no integrado dou uma prova prática e uma prova teórica por bimestre e mais cinco atividades avaliativas. Depois dou uma prova substitutiva para quem perdeu alguma atividade avaliativa ou se quiser melhorar alguma nota. No superior dou três provas práticas, três provas teóricas e quatro atividades avaliativas no semestre". (respondente B) 
O respondente $C$ respondeu que na avaliação escrita o conteúdo é dado e é feito exercício para que possa haver fixação de conteúdo e depois é feito avaliação individual ou em dupla, enquanto que a aula prática é realizada e vale de zero a três. Afirmou, ainda, que "dou um prazo de duas semanas para entrega de relatório escrito que vale de zero a sete pontos" (respondente C). A duas notas são somadas obtendo-se a nota da prática realizada.

O respondente $D$ distribui suas avaliações em quatro etapas: pesquisa por parte do aluno; exposição do assunto e interação continua com os alunos; resolução de lista de exercícios; avaliação escrita. $O$ respondente $E$ informou que para avaliação escrita, costuma trabalhar o conteúdo teórico primeiro, posteriormente, trabalha exercícios de revisão e por fim, aplica a prova. O respondente $F$ disse estabelecer três passos: exposição dos conteúdos com slide, apostilas e exercícios, correção, tira as dúvidas dos alunos e, finalmente, aplica a avaliação.

Quanto ao segundo questionamento, referente as etapas e o que é feito durante as etapas de avaliação, observa-se que os docentes planejam as avaliações de acordo com as etapas bimestrais ou semestrais dos cursos. Outro aspecto relevante é que ao discorrerem sobre o que é feito em cada etapa, a ênfase está na quantidade das aplicações das avaliações, em suas utilidades e mensurações. Por exemplo, o respondente $\mathrm{A}$ afirmou que a avaliação escrita é composta de teoria mais exercícios e mais prova escrita. Da mesma maneira, as atividades de laboratórios são avaliadas a teoria mais prática e, por fim, a elaboração do relatório.

$O$ respondente $B$ detalhou que nos cursos técnicos de nível médio integrado, aplica uma prova prática e uma prova teórica por bimestre e mais cinco atividades avaliativas. Depois aplica uma prova substitutiva para quem perdeu alguma atividade avaliativa ou para quem quiser melhorar alguma nota. Por outro lado, nos cursos superiores de tecnologia, aplica três provas práticas, três provas teóricas e quatro atividades avaliativas no semestre. Essa ação específica caracteriza uma distinção entre as avaliações aplicadas nos cursos de nível médio e nos cursos superiores.

Quadro 2 -

Etapas do processo de avaliação.

\begin{tabular}{|c|c|c|c|c|c|c|c|}
\hline \multicolumn{7}{|c|}{ Etapas da avaliação } \\
\hline Respondente & $\begin{array}{l}\text { Apresentação } \\
\text { de conteúdo }\end{array}$ & $\begin{array}{l}\text { Resolução } \\
\text { de } \\
\text { exercícios }\end{array}$ & $\begin{array}{l}\text { Pesquisa } \\
\text { pelo } \\
\text { aluno }\end{array}$ & $\begin{array}{l}\text { Revisão } \\
\text { de } \\
\text { dúvidas }\end{array}$ & $\begin{array}{l}\text { Avaliação } \\
\text { escrita }\end{array}$ & $\begin{array}{l}\text { Avaliação } \\
\text { prática ou } \\
\text { relatório }\end{array}$ & $\begin{array}{l}\text { Avaliação } \\
\text { substitutiva }\end{array}$ \\
\hline A & $\mathrm{X}$ & $\mathrm{X}$ & & & $\mathrm{X}$ & $\mathrm{X}$ & \\
\hline $\mathrm{B}$ & & & & & $\mathrm{X}$ & $\mathrm{X}$ & $\mathrm{X}$ \\
\hline $\mathrm{C}$ & $\mathrm{X}$ & $\mathrm{X}$ & & & $\mathrm{X}$ & $\mathrm{X}$ & \\
\hline $\mathrm{D}$ & $\mathrm{X}$ & $\mathrm{X}$ & & $\mathrm{X}$ & $\mathrm{X}$ & \\
\hline $\mathrm{E}$ & $\mathrm{X}$ & & & $\mathrm{X}$ & & & \\
\hline $\mathrm{F}$ & $\mathrm{X}$ & & & $\mathrm{X}$ & & & \\
\hline
\end{tabular}

Fonte: autores (2018).

O respondente $C$ descreveu que na avaliação escrita o conteúdo é dado e feito exercício para que possa haver fixação de conteúdo e depois é feito avaliação individual ou em dupla. Destacam-se, aqui, as características da avaliação em seu aspecto de 
'gravar na memória' ou 'decora" conteúdos, apesar de acrescentar a interação entre os estudantes ao permitir avaliações em dupla de estudantes. Por sua vez, a aula prática é realizada e vale de zero a três. É dado um prazo de duas semanas para entrega de relatório escrito que vale de zero a sete pontos. A duas notas são somadas obtendo-se a nota da prática realizada. Nestas circunstâncias, a avaliação se restringe a capacidade de memorização dos alunos e ao somatório das atividades avaliativas as quais são submetidos.

$O$ respondente $D$ detalhou as fases preparatórias para as avaliações como a pesquisa por parte do aluno, a exposição do assunto e interação com os alunos, a resolução de lista de exercícios e a avaliação escrita. Esse modelo pressupõe revisões preparatórias para as avaliações. Não muito diferente dos demais o respondente $E$ afirmou que a para avaliação escrita trabalha o conteúdo teórico primeiro, depois trabalha exercícios de revisão e, por fim, aplica a prova. $O$ responde $F$ disse organizar suas atividades avaliativas em três passos: exposição dos conteúdos com slides, apostilas e exercícios; correção e esclarecimento de dúvidas; avaliação.

Em síntese, pode-se deduzir que as etapas das avaliações para os docentes do ensino profissional obedecem ao mesmo padrão de procedimentos, tais como: apresentação dos conteúdos, resolução de exercícios em sala de aula, revisão de conteúdo e aplicação da prova escrita. Observa-se, também, uma limitação de uso de técnicas de ensino e de instrumentos de avaliação da aprendizagem, assim como a ausência de parâmetros conceituais, procedimentais e atitudinais no processo da avaliação da aprendizagem.

De um modo geral os docentes, em sala de aula, utilizam a prova escrita como avaliação que irá medir a capacidade de armazenamento dos conteúdos teóricos dos componentes curriculares pelos discentes. Esse tipo de avaliação apareceu como predominante nas respostas dos cinco participantes. Outro fato importante que surgiu durante a pesquisa foi a apresentação de um outro espaço pedagógico, além da sala de aula, que foi o laboratório e as aulas práticas.

As avaliações práticas foram o segundo maior tipo de avaliação praticada pelos professores na instituição de ensino. Com isso verificou-se que o espaço de sala de aula é um reduto exclusivo para destinação das avaliações de cunho teórico, ao passo que os laboratórios são utilizados para as atividades e avaliações de cunho da prática. Por conseguinte, percebe-se dois tipos de avaliações para dois tipos de espaço pedagógico distintos, ou seja, sala de aula para as avalições escritas e teóricas e o laboratório para as avaliações e atividades práticas. No mais, em todos os dois tipos de avaliações observouse a ausência de avaliações sistemáticas de caráter processual e etapas de reavaliação da aprendizagem, como também, pouca participação dos alunos.

\section{Conclusão}

Esse estudo mostrou que não existe avaliação participativa nos espaços pedagógicos de educação profissional e tecnológica estudados. Demonstrou-se que os alunos não são consultados no processo de avaliação da aprendizagem, ratificando-se que não há espaço para interação dialogada nos momentos avaliativos, tão pouco é 
solicitada a participação dos alunos por meio de auto-avaliações ou outras formas de avaliações. Por meio da análise dos dados, essa pesquisa mostrou ainda que existe a avaliação teórica e prática como os dois tipos de avaliações mais praticadas pelos professores da educação básica e superior da região norte do Brasil.

Tanto a avaliação teórica quanto a prática são tipos de avaliações da aprendizagem presentes na prática docente e nos espaços pedagógicos da sala de aula e no laboratório. As formas de condução do trabalho docente, tais como exposição dos conteúdos para os alunos, revisão de conteúdo, resolução de exercícios a aplicação do instrumento de avaliação, aparecem nessa pesquisa como descrição de como são feitas as avaliações escritas e práticas. Por tanto, as etapas da avaliação escrita e prática ocorrem mediante as atividades docentes que privilegiam a sequência da apresentação de conteúdo, revisão de conteúdo, exercícios de fixação e aplicação da prova teórica.

\section{Referências}

ALA-HARJA, Marjukka; HELGASON, Sigurdur. Em direção as melhores práticas de avaliação. Revista do Serviço Público, Brasília, v. 51, n. 4, 2000, p. 5-60.

BARKI, Henri; HARTWICK, Jon. Rething the concept of user involvement. Mis Quartely, v. 13, n. 1, 1989, p. 53-63.

BLASIS, Eloisa de. Avaliações em larga escala: contribuições para a melhoria da qualidade na educação. Cadernos Cenpec, São Paulo, v. 3. n. 1, 2013, p. 251-268.

BOROWICC, Roseli; ZOTTI, Solange Aparecida. Planejamento coletivo por temas e avaliação descritiva em escola do campo: a experiência da escola básica municipal José Maria. Revista Linhas, Florianópolis, v. 19, n. 39, 2018, p. 55-79.

BOTH, Ivo José; HARACEMIV, Sonia Maria Chaves. Filosofia, avaliação e neurociência com aporte metodológico e pedagógico de tecnologia. Revista Intersaberes, Curitiba, v. 12, n. 27, 2017, p. 596-605.

BRANDALISE, Mary Ângela Teixeira. Avaliação institucional da escola: conceitos, contextos e práticas. Olhar de professor, Ponta Grossa, v. 13, n. 2, 2010, p. 315-330.

CAIXETA, Michele Caroline Bruno Ferrari; FABRICIO, Márcio Minto. Métodos e instrumentos de apoio ao codesign no processo de projeto de edifícios. Ambiente Construído, Porto Alegre, v. 18, n. 1, 2018, p. 111-131.

CARVALHO, Alexandra; RODRIGUES, Marta. FAP no bairro: uma lógica de desenvolvimento comunitário no Bairro do Carriçal. IS Working Paper, Porto, v. 3, n. 63, 2018, p. 1-24.

CORNWALL, Andrea. Democratizing engagement: what the UK can learn from internacional experience. Londom: Demos, 2008.

CRUZ, Fabrício Nascimento; ALMEIDA, Denise Ribeiro. Avaliação participativa como fundamento para ampliar a percepção do impacto das tecnologias digitais na educação: impressões presentes na realidade e no discurso de um sujeito coletivo. Rigs - Revista Interdisciplinar de Gestão Social, Salvador, v. 6, n. 3, 2017, p. 95-124.

DAMODARAN, Leela. User involvement in the systems design process-a practical guide for users. Behaviour \& information technology, v. 15, n. 6, 1996, p. 363-377.

DEDERING, Kathrin; MÜLLER, Sabine. School improvement through inspections? First empirical insights from Germany. Journal of Educational Change, v. 12, n. 3, 2011, p. 301322. 
FERNANDES, Marina Gonçalves. Educação ambiental como meio para o desenvolvimento local: contributo de quatro instituições da região de Bragança. Bragança: IPB, 2015. 100f. Dissertação (Mestrado em Educação Ambiental). Instituto Politécnico de Braganca.

FIGUEIREDO, Carla; LEITE, Carlinda; FERNANDES, Preciosa. Uma tipologia para a compreensão da avaliação de escolas. Revista Brasileira de Educação, Rio de Janeiro, v. 23, 2018, p. 1-25.

GARIBOLDI, Antonio; PUGNAGHI, Antonella. Relação educativa, avaliação e trabalho de equipe. Revista Linhas, Florianópolis, v. 19, n. 40, 2018, p. 94-115.

GOULART, Jefferson Oliveira; TERCI, Eliana Tadeu; OTERO, Estevam Vanale. Revista Brasileira de Gestão Urbana, Curitiba, v. 7, n. 1, 2015, p. 122-135.

JANSSENS, Frans J. G; VAN AMELSVOORT, Gonnie H. W. C. H. School self-evaluations and school inspections in Europe: an exploratory study. Studies in Educational Evaluation, v. 34 , n. 1, 2008, p. 15-23.

KUDO, Stephany Anry; PEREIRA, Henrique dos Santos; SILVA, Suzy Cristina Pedroza da. A proteção jurídica dos fragmentos florestais urbanos: um estudo da paisagem e da legislação ambiental e Urbanística da cidade de Manaus. Desenvolv. Meio Ambiente, Curitiba, v. 38, 2016, p. 521-540.

LACERDA, Leo Lynce Valle de; FERRI, Cássia; DUARTE, Blaise Keniel da Cruz. SINAES: evaluation, accountability and performance. Avaliação: Revista da Avaliação da Educação Superior, Campinas, v. 21, n. 3, 2016, p. 975-992.

MALTA, Renata Patrícia Duarte. Deixem que eu me re-encontre. Porto: IPP, 2015. $194 f$. Projeto de dissertação (Mestrado em educação e intervenção social). Instituto Politécnico, Universidade do Porto.

MOKATE, Karen Marie. Convertendo o monstro em aliado: a avaliação como ferramenta da gerencia social. Revista do Serviço Público, Brasília, v. 53, n. 1, 2002, p. 89-134.

MOURA, Marcelo Pinto Coelho. A avaliação institucional como instrumento de gestão estratégica: estudo de caso em uma escola estadual de Itabira/MG. Juiz de Fora: UFJF, 2017. 156f. Dissertação (Mestrado Profissional em Gestão e Avaliação da Educação Pública). Universidade Federal de Juiz de Fora.

NASCIMENTO-E-SILVA, Daniel. Compreendendo o processo gerencial. Manaus: Ifam, 2011.

NASCIMENTO-E-SILVA, Daniel. Manual de redação para trabalhos acadêmicos: position paper, ensaios teóricos, artigos científicos, questões discursivas. São Paulo: Atlas, 2012.

NASCIMENTO-E-SILVA, Daniel; SIMÕES, Chiara da Silva; SOARES, Márison Luiz; PEREIRA, Ana Maria Alves. Proposição de uma sistemática de avaliação de aprendizagem na formação de administradores com base no processo gerencial. Rev. Adm. Universidade Federal de Santa Maria, Santa Maria, v. 6, n. 4, 2013, p. 640-657.

NICHOLS, Bruno Washington. A participação radicalizada relacionada a Aécio neves e Dilma Rousseff nas Fanpages de quality papers brasileiros em 2014. Curitiba: UFPR, 2018. 130f. Dissertação (Mestrado em Comunicação Social). Universidade Federal do Paraná.

OLIVEIRA, Cleide Pereira. Avaliação institucional na educação básica: limitações e possibilidades. Salvador: Uneb, 2013. 178f. Dissertação (Mestrado em Gestão e Tecnologias Aplicadas à Educação). Universidade do Estado da Bahia. 
PAULA, Alisson Slider do Nascimento; COSTA, Frederico Jorge Ferreira; LIMA, Kátia Regina Rodrigues. A condicionalidade do estado avaliador e suas implicações na avaliação e a expansão mercantilizada da educação superior brasileira. Rev. Inter. Educ. Sup., Campinas, v. 4, n. 2, 2017, p. 330-346.

RAMOS, Marília Patta; SCHABBACH, Letícia Maria. O estado da arte da avaliação de políticas públicas: conceituação e exemplos de avaliação no Brasil. Revista de Administração Pública-RAP, Rio de Janeiro, v. 46, n. 5, 2012, p. 1271-1294.

RIBEIRO, Paulo. Mobilidade sustentável em arruamentos urbanos e o processo de participação pública (stakeholders). In: ARAÚJO, Emilia; RIBEIRO, Rita; ANDRADE, Pedro; COSTA, Rosalina (eds.). Viver em/la mobilidade: rumo a novas culturas de tempo, espaço e distância. Braga: Cecs, 2018, p. 95-113.

ROESCH, Sylvia Maria Azevedo. Avaliação: gerar conhecimento tecnocrático ou capacidade local? In: FISCHER, Tânia (org.). Gestão do desenvolvimento e poderes locais: marcos teóricos e avaliação. Salvador: Casa da Qualidade, 2002.

SABIONI, Marjorie; FERREIRA, Marco Aurélio Marques; REIS, Anderson de Oliveira. Racionalidades na motivação para a participação cidadã no controle social: uma experiência local brasileira. Cad. EBAPE.BR, Rio de Janeiro, v. 16, n. 1, 2018, p. 81-100.

SANTOS, Letícia Carvalho; SANTOS, Luiza Carvalho. A avaliação na educação infantil. Revista Multidebates, Palmas, v. 2, n. 1, 2018, p. 1-15.

THOENIG, Jean-Claude. A avaliação como conhecimento utilizável para reformas de gestão pública. Revista do Serviço Público, Brasília, v. 51, n. 2, 2000, p. 54-71.

VIANNA, Iara Lima; AMARAL, Ernesto Friedrich de Lima. Utilização de metodologias de avaliação de políticas públicas no Brasil. In: AMARAL, Ernesto Friedrich de Lima; GONÇALVES, Guilherme Quaresma; FAUSTINO, Samantha Haussman Rodarte (orgs.). Aplicações de técnicas avançadas e avaliação de políticas públicas. Belo Horizonte: Fino Traço, 2014, p.15-38.

VILLA, Simone Barbosa; SARAMAGO, Rita de Cássia Pereira; ARAÚJO, Débora Cristina. Avaliação pós-ocupação no ensino de projeto de arquitetura: uma experiência didáticopedagógica na disciplina Atelier de Projeto Integrado V. Gestão e Tecnologia de Projetos, São Carlos, v. 13, n. 1, 2018, p. 7-20.

Maria Raimunda Lima Valle é estudante no Mestrado Profissional em Educação Profissional e Tecnológica no Instituto Federal do Amazonas.

Orcid: https://orcid.org/0000-0001-5700-1600.

Endereço: Rua Rio Branco, 664 - 69027-030 - Manaus - AM - Brasil.

E-mail: mrlv.bianca@gmail.com.

Daniel Nascimento-e-Silva é professor no Instituto Federal do Amazonas.

Orcid: https://orcid.org/0000-0001-9770-575X.

Endereço: Rua André Thevet, 11- 69098-325 - Manaus - AM - Brasil.

E-mail: danielnss@gmail.com. 
Ronison Oliveira da Silva é estudante no Mestrado Profissional em Educação Profissional e Tecnológica no Instituto Federal do Amazonas.

Orcid: https://orcid.org/0000-0003-0709-4081.

Endereço: Rua Monte Calvário, 83 - 69039-710 - Manaus - AM - Brasil.

E-mail: ronison.msc@gmail.com.

Recebido em 22 de outubro de 2019.

Aceito em 17 de dezembro de 2019.

(c) (i) 